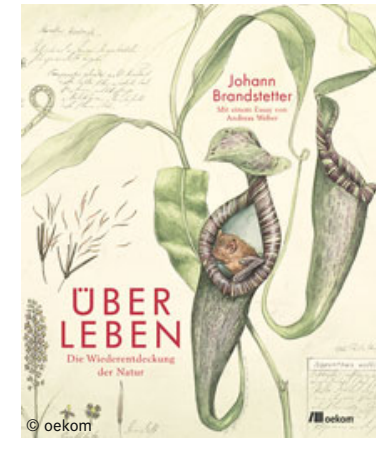

\section{ÜBER LEBEN}

Die Wiederentdeckung der Natur

Johann Brandstetter Mit einem Essay von Andreas Weber

112 S., zahlreiche Abb., oekom, 2019. HC, $39,00 €$.

ISBN: 9783962381332

DOI: $10.1007 / \mathrm{s} 12268-020-1359-5$

(C) Springer-Verlag GmbH 2020

Was soll ich als mittelmäßige Hobbyzeichnerin über ein Buch des preisgekrönten Künstlers Johann Brandstetter schreiben? Brandstetter erscheint als einer der bekanntesten Illustratoren gleich mehrmals auf der Liste der 200 Best Illustrators Worldwide. Vielleicht dies: Lassen Sie sich von den Skizzen, Zeichnungen und Aquarellen zum Betrachten verführen, zu Ruhe und Konzentration. Entdecken Sie gleichzeitig den Lebensraum eines Lebewesens und Details seiner Anatomie. ÜBER LEBEN ist kein Buch, das man verschlingt, sondern eines, das zum Verweilen, zum Vertiefen und zum Genießen einlädt. Viele Bilder erzählen eine ganze Geschichte.

Eingerahmt sind die großartigen Abbildungen von einem Essay von Andreas Weber und einem Interview mit dem Künstler selbst. So erzählt Herr Brandstetter am Ende des Buches unter anderem, wie er zum Malen gekommen ist, was es inm selbst bedeutet und was sein Ziel ist. „Wenn ich beim Betrachter erreiche, dass er zu staunen beginnt und vielleicht in seinem eigenen Garten dann anders und wohlwollender auf In- sekten schaut, ist mein Projekt geglückt.“

Mir würde das Buch noch besser gefallen, wenn es mehr einheimische Bildergeschichten erzählen würde. Der Untertitel sagt, es geht um die Wiederentdeckung der Natur. Wir haben doch genug eigene Probleme mit dieser Natur vor unserer Haustür: mit dem Aussterben der Insekten einerseits und mit dem Einwandern von Wolf, Luchs und Biber andererseits, um nur einige zu nennen. Ein wenig suggeriert mir die Bildauswahl: „Ich muss erst verreisen und irgendwohin fliegen, damit ich etwas entdecken kann." Früher habe ich tatsächlich so gedacht und so gehandelt und die Faultiere in Mittelamerika und die Löwen in Afrika gesucht und fotografiert. Seit ich zeichnend die bizarre Schönheit und Vielfalt direkt vor meinen Füßen entdecke, habe ich das Gefühl, angekommen zu sein und nicht mehr suchend wegfliegen zu müssen.

Ursula Loos, Heidelberg, kontakt@ursula-loos.de 